\title{
Acinetobacter baumannii: trends in antimicrobial resistance after relocation of an intensive care unit in tunisia
}

\author{
S Koubaji, S Kamoun, A Ben Souissi, F Haddad, Y Ben Aicha, MS Mebazaa \\ From ESICM LIVES 2015 \\ Berlin, Germany. 3-7 October 2015
}

\section{Purpose}

Multidrug-resistant Acinetobacter Baumannii (MDRAB) is a worldwide threat because of its remarkable ability to survive in harsh environment for months. It has been shown that MDRAB can colonize patient environment [1], especially in intensive care units (ICU). This study aims to compare the prevalence and antimicrobial susceptibility pattern of Acinetobacter Baumannii infecting ICU patients before and after relocation.

\section{Methods}

A retrospective study including all patients with Acinetobacter Baumannii $(\mathrm{AB})$ infections, admitted in ICU between January 2013 and January 2015; the relocation occurred in September 2013. We recorded the site of infection, the antimicrobial susceptibility, antibiotic therapy and the outcome.

\section{Results}

310 patients were hospitalized in intensive care unit: 160 in the old location and 150 in the new one. Among the 310 patients, 36 developed infection with $\mathrm{AB}$ isolated in 45 cultures: 17 in the old location and 19 in the new one. In the old location, isolates were resistant to imipenem in $66 \%, 100 \%$ to amikacin, $100 \%$ to quinolones, and $16 \%$ susceptible to fosfomycin, $94.11 \%$ susceptible to colistin, $94 \%$ to rifampicin and $100 \%$ to tigecycline, however in the new location, we noted $95 \%$ resistance to imipenem, $21 \%$ resistance to amikacin, $100 \%$ resistance to quinolones, and $20 \%$ susceptibility to fosfomycin, $100 \%$ to colistin, $94.7 \%$ to rifampicin and $100 \%$ susceptible to tigecycline. All

Mongi Slim University Hospital La Marsa, Anesthesiology and ICU Department, Sidi Daoued, Tunisia

(c) 2015 Koubaji et al.; This is an Open Access article distributed under the terms of the Creative Commons Attribution License (http:// creativecommons.org/licenses/by/4.0), which permits unrestricted use, distribution, and reproduction in any medium, provided the original work is properly cited. patients have received a combination therapy adapted to microbiological findings: $2.7 \%$ Fosfomycin + colistin, $13.8 \%$ imipenem + colistin, $38.8 \%$ colistin + Rifampicin, $44.7 \%$ Tigecycline + colistin. The mortality rate was 72.3\%: $74 \%$ related to refractory septic shock and $26 \%$ due to different causes.

\section{Discussion}

The main risk factors for nosocomial infections in ICUs are: assisted ventilation, large prescription of antibiotics, prolonged hospital stay and catheterization. Stringent measures had to be applied: restricted policy tion of the environment and even the closure of the unit. Furthermore, the resistance of the $A B$ affects different classes of antibiotics such as carbapenems. However, resistance to imipenem is variable according to the authors, ranging from 3.1 to $60 \%$ [2]. No resistance of $A B$ to colistin was found according to various studies [3]. For multidrug-resistant AB, the antibiotherapy with colistin, rifampicin and tigecycline [4] have been associated with" favorable" clinical outcomes.

\section{Conclusions}

The spread of multidrug-resistant $A B$ in ICU presents a challenge to clinician. It is necessary to intensify efforts to respect hygiene rules and restriction in the use of antibiotics.

\section{Published: 1 October 2015}

\section{References}

1. Fournier PE: Clin Infect Dis 2006, 42:692-9.

2. Picazo JJ: Enferm Infecc Microbiol Clin 2006, 24:617-28. for the use of specific drugs, septic isolation, disinfec- 
3. Li J: Int J Antimicrob Agents 2005, 25:11-25.

4. Garnacho-Montero J: Curr Opin Infect Dis 2010, 23:332-9.

doi:10.1186/2197-425X-3-S1-A135

Cite this article as: Koubaji et al:: Acinetobacter baumannii: trends in

antimicrobial resistance after relocation of an intensive care unit in

tunisia. Intensive Care Medicine Experimental 2015 3(Suppl 1):A135.

\section{Submit your manuscript to a SpringerOpen ${ }^{\circ}$ journal and benefit from:}

- Convenient online submission

- Rigorous peer review

- Immediate publication on acceptance

- Open access: articles freely available online

- High visibility within the field

- Retaining the copyright to your article

Submit your next manuscript at $\gg$ springeropen.com 